\title{
MicroRNA-16 inhibits the migration and invasion of glioma cell by targeting $\mathrm{Bcl}-2$ gene
}

\author{
Baochang Luo ${ }^{1}$, Jing Zhang ${ }^{2 *}$ \\ ${ }^{1}$ Department of Neurosurgery, ${ }^{2}$ Department of Clinical Laboratory, Hanchuan People's Hospital, Hanchuan City, Hubei \\ Province, China \\ *For correspondence: Email: ejkbv6@163.com
}

Sent for review: 22 September 2020

Revised accepted: 2 December 2020

\begin{abstract}
Purpose: To investigate the effect of microRNA-16 (miR-16) on glioma cell migration and invasiveness, and the mechanism involved.

Methods: MicroRNA-16 mimic or inhibitor was transfected into human glioma (SHG44) cells. Cell migration, invasiveness and morphology were determined using scratch test, Transwell invasion assay, and immunohistochemical staining, respectively. Expressions of bcl-2, MMP-9 and MMP-2, and NF-kB1 proteins were measured using Western blotting.

Results: Overexpression of MicroRNA-16 significantly down-regulated MMP-9 protein in SHG44 cells $(p<0.05)$, but MMP-2 protein expressions in the 2 groups were comparable $(p>0.05)$. Protein expressions of MMP-9 and NF-KB1 were significantly down-regulated in human glioma positive cells, relative to negative control.

Conclusion: MiR-16 overexpression suppresses the migration and invasiveness of SHG44 cells via the regulation of NF-KB1/MMP-9 signaling pathway, and it directly targets bcl-2 gene by inhibiting its protein expression. This finding affords a new target for developing new anti-glioma drugs.
\end{abstract}

Keywords: Bcl-2, Expression, Glioma, MicroRNA-16, NF-KB1signaling pathway

\begin{abstract}
This is an Open Access article that uses a funding model which does not charge readers or their institutions for access and distributed under the terms of the Creative Commons Attribution License (http://creativecommons.org/licenses/by/4.0) and the Budapest Open Access Initiative (http://www.budapestopenaccessinitiative.org/read), which permit unrestricted use, distribution, and reproduction in any medium, provided the original work is properly credited.

Tropical Journal of Pharmaceutical Research is indexed by Science Citation Index (SciSearch), Scopus, International Pharmaceutical Abstract, Chemical Abstracts, Embase, Index Copernicus, EBSCO, African Index Medicus, JournalSeek, Journal Citation Reports/Science Edition, Directory of Open Access Journals (DOAJ), African Journal Online, Bioline International, Open-J-Gate and Pharmacy Abstracts
\end{abstract}

\section{INTRODUCTION}

Glioma, a highly invasive cancer tumor that originates from brain or spinal cord glial cells, accounts for $80 \%$ of brain malignancies. Glioma treatments include surgery, radiation therapy, chemotherapy and targeted molecular therapy [1].

MicroRNAs (miRNAs) have been implicated in the pathogenesis of gliomas. They function as proto-oncogenes or tumor suppressor genes which regulate the degradation and translation of mRNA [2]. The expression of miR-16 is downregulated in malignant tumors such as prostate and lung cancer [3]. Studies have also revealed a close association between miR-16 expression and human glioma.

Apoptosis and necrosis, two major forms of cell death, are universal biological phenomena [4]. The proliferative capacity of tumor cells is due to their ability to resist apoptosis. 
B-Cell lymphoma 2 (bcl-2), an oncogene located in mitochondria, is both pro-apoptotic and antiapoptotic. As a pro-apoptotic regulatory gene, bcl-2 is involved in the pathogenesis of several diseases [5]. Impairment of the bcl-2 gene is associated with anti-cancer drug resistance and etiology of some tumors [6]. Studies have shown that in patients with chronic myelogenous leukemia, the expressions of miR-15a and miR16-1 are markedly down-regulated, while bcl-2 protein expression is significantly upregulated [7]. However, the precise molecular mechanism underlying the involvement of miR-16 and bcl-2 in the initiation and progression of gliomas has not been fully elucidated. The influence of miR16 on glioma cell migration and invasiveness, and mechanism involved, were the aim of the present study.

\section{EXPERIMENTAL}

\section{Materials}

Human glioma SHG44 cells were obtained from Guangzhou Ginio Biotech Company Limited, China. The BALB/C nude mice used for this study were obtained from Wuhan Yunclone Diagnostic Reagent Research Institute Co. Ltd, China. Rabbit MMP-2, MMP-4, NF-kB1 monoclonal antibodies, real-time fluorescent quantitative PCR reagent, RPMI 1640 medium, DMEM, FBS, trypsin and miR-16 primer were products of Shanghai Biotechnology Co. Ltd. (China). Carbon IV oxide $\left(\mathrm{CO}_{2}\right)$ incubator, ultraclean bench, inverted microscope, bench-top high-speed centrifuge, constant temperature water bath, electronic scale, ultra-low temperature refrigerator, PCR machine, Transwell cell chamber, microtome, embedding machine, optical and fluorescence microscope, electrophoresis tank, and electric transfer tank were purchased from Dalian (China).

\section{Cell culture}

The SHG44 cells were maintained for $24 \mathrm{~h}$ in DMEM tainted with $10 \%$ FBS and antibiotics in a $5 \% \mathrm{CO}_{2}$ incubator. Logarithmic growth phase cells were selected and used for the study.

\section{Cell transfection}

Liposome transfection method was employed with lipofectamine 2000 transfection reagent. The cells were seeded in 6-well plates until they attained 40 - $50 \%$ fusion. The cells were cultured in serum-free medium with equal volume of miR-16 mimic or inhibitor, each at a concentration of $10 \mu \mathrm{mol} / \mathrm{L}$. Incubation was done at laboratory temperature for $5 \mathrm{~min}$.
Lipofectamine 2000 was dissolved in serum-free medium and incubated at laboratory temperature for $10 \mathrm{~min}$ to form a mixture. The mixture was then added to cells in each group, and cultured at $37^{\circ} \mathrm{C}$ in a $5 \% \mathrm{CO}_{2}$ atmosphere for $48 \mathrm{~h}$. Normal cell culture without miR-16 mimics or inhibitor served as control group. The transfection efficiency was determined with qRTPCR.

\section{Immunoblot assay}

After transfection, the SHG44 cells were assigned to three groups: control group, miR-16 mimic group and miR-16 inhibitor group. The levels of expression of bcl-2, miR-16, MMP-9 and MMP-2 in each group were determined using Western blotting. The cells were rinsed in PBS and lysed with ice-cold radio-immunoprecipitation assay (RIPA) buffer containing protease and phosphatase inhibitors. The protein obtained after centrifugation was quantified, subjected to SDS-PAGE, transferred to PVDF membranes which were then blocked with skim milk and incubated overnight at $4{ }^{\circ} \mathrm{C}$ with rabbit $1^{\circ}$ polyclonal antibodies against bcl-2, miR-16, MMP- 9, MMP-2 and $\beta$ actin, all diluted 1 to 1000 , followed by incubation for $60 \mathrm{~min}$ with HRP-linked $2^{\circ}$. Blot development was done with X-ray film, and the bands were subjected to Grayscale analysis with enhanced chemiluminescence (ECL). The $\beta$-actin protein served as standard.

\section{Cell migration assay}

The migratory ability of SHG44 cells was determined using scratch test. The cells were seeded in 6-well plates until they attained 90 $100 \%$ confluency, and scratches were made on the cell monolayers. After washing thrice with serum-free medium, the cells were further cultured for $72 \mathrm{~h}$, and then observed and analyzed using Image Pro Plus (6.0). Cell mobility $(C M)$ was calculated as shown in Eq 1.

$\mathrm{CM}=(1-\mathrm{S} \times 100 \%) /(\mathrm{IS})$

where $S$ is scratch width during measurement, and $I S$ is initial scratch width.

\section{Determination of cell invasiveness}

The degree of invasiveness of SHG44 cells was determined using Transwell invasion assay. The cells were placed in Transwell chamber at a density of $1 \times 10^{5}$ cells $/ \mathrm{mL}$, coated with substrate, and cultured without serum, while 10 $\%$ FBS medium was placed in the lower compartment. Following $24 \mathrm{~h}$ culture, cells that 
passed through the matrix gel membrane were subjected to staining with crystal violet after fixation, photographed and counted using an inverted microscope.

\section{Transfection of mice with glioma cells}

Nude mice (BALB/C) weighing 40 to $50 \mathrm{~g}$ (mean weight $=45.0 \pm 4.11 \mathrm{~g}$ ) and aged $2-3$ weeks were transfected with SHG44 cells $\left(3 \times 10^{6}\right.$ cells) for $48 \mathrm{~h}$ using lipofectamine 2000 transfection kit. The animals were thereafter assigned to 2 groups (7 mice/group): negative and positive control groups. Subcutaneous glioma models were successfully established in both groups. After 6 weeks, the mice were euthanized and hematoxylin and eosin ( $\mathrm{H}$ \& E) staining was used to determine the growth of subcutaneous tumors in both groups of mice.

\section{Immunofluorescence staining (SP method)}

In order to enhance cell dissociation, microspheres were immersed in dissociation solution containing $0.9 \% \mathrm{NaCl}, 55 \mathrm{mM}$ sodium citrate, and $20 \mathrm{mM}$ ethylenediaminetetraacetate (EDTA) for $5 \mathrm{~min}$. The cells were thereafter collected and re-plated at $37^{\circ} \mathrm{C}$ for $12 \mathrm{~h}$ to allow them adhere properly to the plates. The two groups were subjected to fixation in paraformaldehyde at laboratory temperature for 30 min and treated with $0.1 \%$ Triton X-100 for 20 min. Primary antibodies for MMP-9 and NF-KB1 were added, followed by overnight incubation before the secondary antibodies were applied.

\section{Statistics}

Results are shown as mean \pm SEM. Two-group comparison was done with $t$-test using version SPSS 23.0. Values of $p<0.05$ implied significant differences.

\section{RESULTS}

Expression levels of $\mathrm{Bcl}-2$ and $\mathrm{miR}-16$ in SHG44 cells after transfection

Table 1 shows that the expression of bcl- 2 was significantly down-regulated in miR-16 mimic group, relative to control $(p<0.05)$. The corresponding miR-16 expression was markedly upregulated in mimic group, but was downregulated in cells exposed to inhibitor $(p<0.05)$.

\section{Effect of miR-16 overexpression on migratory and invasive potential of human SHG44 cells}

The migratory ability of cells in miR-16 mimic group was significantly lower than that of control group, and the mean number of cells migrating in the inhibitor group was markedly higher than that in control ( $p<0.05$; Figure 1).

Table 1: Protein expressions of bcl-2 and miR-16 in SHG44 cells

\begin{tabular}{lcc}
\hline Group & Bcl-2 & miR-16 \\
\hline Control & $9.88 \pm 0.49$ & $5.63 \pm 1.22$ \\
MiR-16 inhibitor & $9.91 \pm 1.23^{\mathrm{b}}$ & $4.55 \pm 1.18^{\mathrm{b}}$ \\
MiR-16 mimic & $2.58 \pm 0.68^{\mathrm{a}}$ & $12.23 \pm 1.56^{\mathrm{a}}$ \\
\hline
\end{tabular}

${ }^{a} P<0.05$, vs control; ${ }^{b} p<0.05$, vs miR-16 mimic

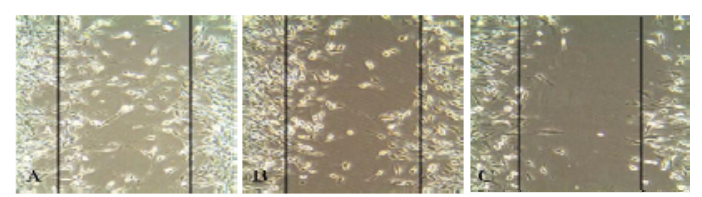

Figure 1: Effect of miR-16 overexpression on the migration of human glioma cells. A: Control group; B: miR-16 inhibitor group; C: miR-16 mimic group

\section{Effect of miR-16 mimic and inhibitor on SHG44 cell invasiveness}

As shown in Figure 2, cells in miR-16 mimic group were less invasive than those in control group, but cell invasiveness was significantly promoted by miR-16 inhibitor $(p<0.05)$.

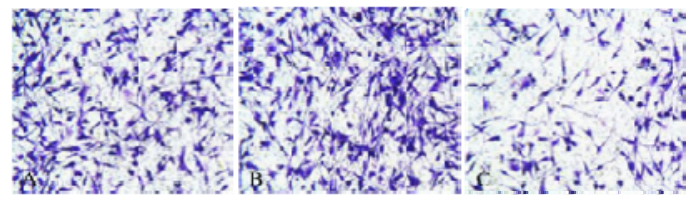

Figure 2: Effect of miR-16 overexpression on the invasion of human glioma cells. A: Control group; B: miR-16 inhibitor group; C: miR-16 mimics group

\section{Effect of miR-16 overexpression on protein levels of MMP-9 and MMP-2 in human glioma cells}

MicroRNA-16 overexpression significantly downregulated MMP-9 protein in SHG44 cells $(p<$ 0.05 ), but had no effect on MMP-2 protein expression (Figure 3).

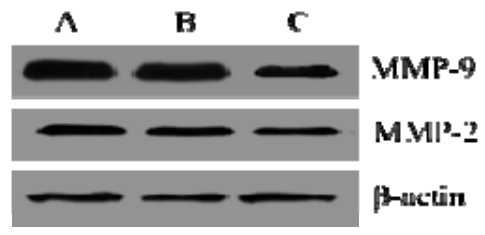

Figure 3: Effect of miR-16 overexpression on MMP-9 and MMP-2 expression levels in human glioma cells. A: Control group; B: miR-16 inhibitor group; C: miR-16 mimic group

Trop J Pharm Res, December 2020; 19(12): 2501 
Influence of miR-16 overexpression on growth and invasiveness of human glioma cells

In the positive control group, immunohistochemical staining revealed visible cell boundary with small tumor volume. However, in the negative control group, the cell boundary was not distinct and was characterized by large tumor volume (Figure 4). As shown in Figure 5, MMP-9 expression level was markedly reduced in positive control group $(p<0.05)$.
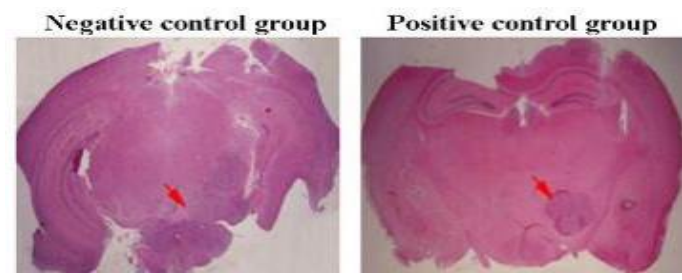

Figure 4: Influence of miR-16 expression on growth of human glioma cells

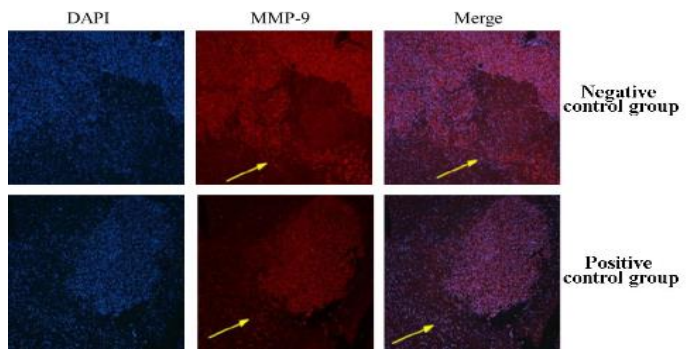

Figure 5: Influence of miR-16 overexpression on MMP-9 level in human glioma.

\section{Effect of miR-16 overexpression on MMP-9} and NF-KB1 expression levels in SHG44 cells

As shown in Figure 6, protein expressions of MMP-9 and NF-kB1 were significantly downregulated in human glioma positive cells, relative to negative control.

\section{DISCUSSION}

Gliomas are one of the common diseases of the nervous system, and account for about $45 \%$ of all intracranial tumors. At present, surgery, radiotherapy and chemotherapy remain the main treatment strategies for glioma, but they are characterized by poor prognosis. Studies have shown that the 1-year survival of patients with glioblastoma multiforme (GBM) is barely $58 \%$, while 2-year survival is only $31 \%$ [8]. This study investigated the impact of miR-16 on glioma cell migration and invasiveness, and the mechanism involved.

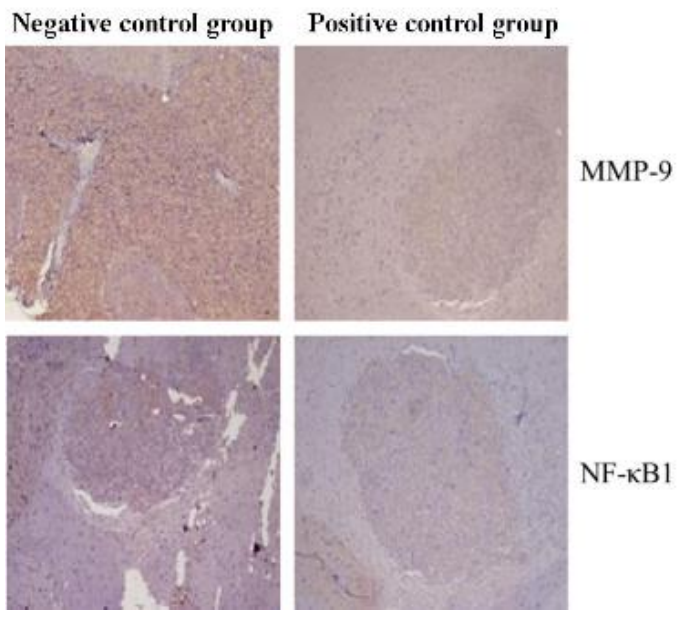

Figure 6: Influence of miR-16 overexpression on MMP-9 and NF-kB1 levels in SHG44 cells

Clinical reports suggest that proto-oncogene activation and tumor suppressor gene inactivation are key in initiation and progression of gliomas [9].

MicroRNA-16 has been implicated in tumorigenesis. Its expression is reduced in prostate and non-small cell lung cancer [10]. It induces apoptosis in small lymphocytic lymphoma cells via down-regulation of bcl-2 expression [11]. However, the precise molecular mechanism involved is yet to be fully elucidated. As a carcinogenic gene, bcl-2 is located primarily in mitochondria, where it participates in the initiation of glioma [12]. The upregulation of bcl-2 expression is associated with increased degree of malignancy of human glioma [13].

Studies have shown that miR-16 protein expression is down-regulated in primary human glioma tissue. The present study showed marked decrease in bcl-2 in miR-16 mimic group, relative to control group. The corresponding miR-16 expression was markedly increased in mimic group, but down-regulated in inhibitor group. These results suggest that miR-16 may directly target bcl-2 gene.

Tumor invasiveness is one of the key factors involved in tumor recurrence. This is responsible for the failure of most cancer therapies. For a particular cancer therapy to be effective, it must effectively address the issue of cancer invasion and metastasis. Disruption of adhesion of cancer cells to the stroma causes tumor cell invasion and metastasis. Matrix metalloproteinase (MMP), a zinc-dependent protein, specifically degrades extracellular matrix and regulates cell adhesion, thereby promoting tumor cell invasion and 
metastasis [14]. Clinical investigations have revealed that protein expressions of MMP-2 and MMP-4 are upregulated in human gliomas $[15,16]$.

Nuclear factor kappa-light-chain-enhancer of activated $B$ cells (NF-kB) signaling pathway regulates tumor cell proliferation and invasion. Thus, it plays a key role in tumor progression and growth. The results of this study indicate that miRNA-16 overexpression inhibited MMP-9 protein expression, thereby slowing down the growth and invasion of glioma cell. Similarly, protein expressions of MMP-9 and NF-KB1 were significantly down-regulated in human glioma positive cells, relative to the negative control cells. These results show that miR-16 suppresses the proliferative and invasive potential of glioma cells via the regulation of NFkB1/MMP-9 signal route.

\section{CONCLUSION}

Findings obtained in this investigation suggest that overexpression of miR-16 suppresses migratory potential and invasiveness of SHG44 cells via the NF-kB1/MMP-9 signal route. It also directly targets bcl-2 gene by inhibiting its protein expression. This provides a new target for the development of new anti-cancer drugs.

\section{DECLARATIONS}

\section{Conflict of interest}

No conflict of interest is associated with this work.

\section{Contribution of authors}

This study was done by the authors named in this manuscript, and the authors accept all liabilities resulting from claims which relate to this article and its contents. The study was conceived and designed by Jing Zhang; Baochang Luo and Jing Zhang collected and analyzed the data, while Baochang Luo wrote the text. All authors read and approved the manuscript for publication.

\section{Open Access}

This is an Open Access article that uses a funding model which does not charge readers or their institutions for access and distributed under the terms of the Creative Commons Attribution License (http://creativecommons.org/licenses/by/ 4.0) and the Budapest Open Access Initiative (http://www.budapestopenaccessinitiative.org/rea d), which permit unrestricted use, distribution, and reproduction in any medium, provided the original work is properly credited.

\section{REFERENCES}

1. Sorensen $M D$, Dahlrot $R H$, Boldt $H B$, Hansen $S$, Kristensen $\quad B W$. Tumour-associated microglia/macrophages predict poor prognosis in high-grade gliomas and correlate with an aggressive tumour subtype. Neuropathol Appl Neurobiol 2018; 44(2): 185-206.

2. Anna $T$, Changho $C$, Bruce $M$. Non-invasive assessment of Isocitrate dehydrogenase (IDH) mutational status in cerebral gliomas by Magnetic Resonance Spectroscopy in a clinical setting. J Neurosurg 2018; 128(2): 1-13.

3. Pinchi E, Frati A, Cipolloni L, Aromatario M, Gatto V, La Russa $R$, Pesce A, Santurro A, Fraschetti $F$, Frati $P$, et al. Clinical-pathological study on $\beta-A P P, I L-1 \beta, G F A P$, NFL, Spectrin?II, 8OHdG, TUNEL, miR-21, miR-16, miR-92 expressions to verify DAl-diagnosis, grade and prognosis. Entific Rep 2018; 8(1): 2387-2391.

4. Liu Z, Wang Y, Wang L, Yao B, Sun L, Liu R, Chen $T$, Niu Y, Tu K, Liu Q. Long non-coding RNA AGAP2-AS1, functioning as a competitive endogenous RNA, upregulates ANXA11 expression by sponging miR-16$5 p$ and promotes proliferation and metastasis in hepatocellular carcinoma. J Exp Clin Cancer Res 2019; 38(1): 194-199.

5. Kallepu S, Kavitha M, Yeeravalli R, Manupati K, Jadav SS, Das A, Mainkar PS, Chandrasekhar S. Total Synthesis of Desmethyl Jahanyne and Its LipoTetrapeptide Conjugates Derived from Parent Skeleton as BCL-2-Mediated Apoptosis-Inducing Agents. Acs Omega 2018; 3(1): 63-75.

6. Song $Y$, Zhong M, Cai FC. Oxcarbazepine causes neurocyte apoptosis and developing brain damage by triggering $\mathrm{Bax} / \mathrm{Bcl}-2$ signaling pathway mediated caspase 3 activation in neonatal rats. Euro Rev Medical Pharmacol Sci 2018; 22(1): 250-258.

7. Wang $F$, Chen L, Zhu S, Wang S, Chen C, Zhang W, Wang $X$, Zhang J, Wang $M$. Sulforaphane Induces Apoptosis of Acute Human Leukemia Cells Through Modulation of Bax, Bcl-2 and Caspase-3. Int J Pharmacol 2018; 1(3): 369-376.

8. Bisdas $S$, Shen $H$, Thust $S$, Katsaros V, Stranjalis G, Boskos C, Brandner S, Zhang J. Texture analysis- and support vector machine-assisted diffusional kurtosis imaging may allow in vivo gliomas grading and IDHmutation status prediction: a preliminary study. Sci Rep 2018; 8(1): 6108-6115.

9. Zhang $K$, Han Y, Zhao Y, Sun Y, Zou M, Fu Y, Peng X. Upregulated gga-miR-16-5p Inhibits the Proliferation Cycle and Promotes the Apoptosis of MG-Infected DF-1 Cells by Repressing PIK3R1-Mediated the PI3KJAkt/NF$\kappa B$ Pathway to Exert Anti-Inflammatory Effect. Int $\mathrm{J} \mathrm{Mol}$ Sci 2019; 20(5): 1-9.

Trop J Pharm Res, December 2020; 19(12): 2503 
10. Wu Z, Lin Y. Long noncoding RNA LINC00515 promotes cell proliferation and inhibits apoptosis by sponging miR16 and activating PRMT5 expression in human glioma. Oncotargets Ther 2019; 12: 2595-2604.

11. Liu Y, Gu S, Li H, Wang J, Wei C, Liu Q. SNHG16 promotes osteosarcoma progression and enhances cisplatin resistance by sponging miR-16 to upregulate ATG4B expression. Biochem Biophys Res Commun 2019; 518(1): 90-98.

12. Pan $Y$, Wang N, Xia P, Wang E, Guo Q, Ye Z. Inhibition of Rac1 ameliorates neuronal oxidative stress damage via reducing $B c l-2 / R a c 1$ complex formation in mitochondria through PI3K/Akt/mTOR pathway. Exp Neurol 2018; 300: 149-166.

13. Wang B, Luo $Y$, Zhou $X$, Li R. Trifluoperazine induces apoptosis through the upregulation of $\mathrm{Bax} / \mathrm{BCl}-2$ and downregulated phosphorylation of AKT in mesangial cells and improves renal function in lupus nephritis mice. Int J Mol Med 2018; 41(6): 3278-3286.

14. Bramhall SR, Stamp GWH, Dunn J, Lemoine NR, Neoptolemos JP. Imbalance of expression of matrix metalloproteinases (MMPs) and tissue inhibitors of the matrix metalloproteinases (TIMPs) in human pancreatic carcinoma. J Pathol 1997; 182(3): 347-355.

15. Li D, Lixia Y, Fengsui L, Haitao Z, Xinwei C. Farrerol ameliorates diabetic hepatopathy in rat model of type 2 diabetes mellitus via modulation of oxidative inflammatory stress. Trop J Pharm Res 2020; 19 (1): 71 76.

16. ShanPing Li, SenMao Hu. Cinnamic hydroxamic acid inhibits the proliferation of gastric cancer cells via upregulation of miR 145 expression and downregulation of P13K/Akt signaling pathway. Trop J Pharm Res 2020; 19 (5): 957-963. 